\title{
Eräitä ranskalaisuuden piirteitä V. A. Koskenniemen esseetyylissä
}

V. A. Koskenniemelle oli ominaista nopea työskentelyrytmi: hän luki ja kirjoitti nopeasti, vastasi välittömästi poleemisiin haasteisiin, tarttui innokkaasti ajankohtaisuuksiin, tavoitti lennosta vaikutelmia - hän reagoi nopeasti ja toimi myös.

Vaikutelma sopii rinnastettavaksi siihen tenniksenpelaajan Kuvaan, jolla Henri Morier eräässä teoksessaan ${ }^{2}$ havainnollistaa ranskalaista tyyliä: lyöntien ilotulitusta, eloisaa intelligenttiä leikkiä :jokin sellainen se ilmentää ranskalaista esprit'tä, ajatus- ja-mielikuvitustoiminnassaan kekseliästä ja nopeaa, vaihtelua rakastavaa.

Olisi tietenkin perusteetonta näin vain panna yhtäläisyysmerkkejä Koskenniemen ja ranskalaisen tyylin välille. Lähdettäessä tarkastelemaan eräitä Koskenniemen esseetyylin ominaisuuksia puhumalla ranskalaisuudesta, nimenomaan klassisesta ranskalaisuudesta, on tarkoituksena käyttää termï tulkinnan apuvälineenä. Siihenkin tarvitaan varovaisuutta - syntyy helposti houkutus nähdä hypoteesin mukaisesti ikään kuin liikaa. Muitakin epäilyksiä tulee mieleen: Olemmeko lähdössä vaikutteiden etsinnän petolliselle tielle? Tiedämmehän vertailevan metodin vaarat.

Emme saa ilman muuta vetää kausaaliyhteyttä jonkin käyttäytymis- ja toimintamuodon ja kirjallisen tyylin välille. Mutta toiminnan muodot valaisevat ajatuksen ja tunteen muotoja: niitä koskee myös ilmaisu. "Le style est l'homme même", kuten Buffon on sanonut.

${ }^{1}$ V. A. Koskenniemen seuran perustavassa kokouksessa Turussa 21. 11. 1965 pidetty esitelmä.

2 Henri Morier, La psychologie des styles, Genève 1959, s. 7. 
Persoonallisuuden merkitystä korostaa myös Morier tyylien psykologiassaan. Tyyliä ei ole ilman olennaisuuksia ja niiden jatkuvuutta. Se edellyttää uskollisuutta omalle itselleen.

V. A. Koskenniemen kirjallisen tyylin piirteet kuuluvat hänen persoonallisuutensa kokonaiskuvaan. On sen vuoksi merkityksellistä, mitä tiedetään hänen työskentelynsä tehokkuudesta, nopeudesta ja journalistisesta luonteesta. Hänen henkilökuvansa piirtäjä Rafael Koskimies ${ }^{3}$ saattaa omien muistojensa mukaan kertoa, että V. A. Koskenniemen "äly. leikkasi kirkkaasti ja kylmästi mutta se osasi myös nauraa" ja että hän kirjallisena väittelijänä oli "hyvin etevä, niin, pelottavakin". - Tämähän koskee tyyliä. Koskenniemen kirjallisen kritiikin Koskimies arvioi olleen lähinnä impressionismia ja rakentuneen "jo varhain saaduille ranskalaisen ja ruotsalaisen esseetaiteen kansainvälisesti arvostetuille saavutuksille: joku Lemaître, Faguet, Oscar Levertin voi tulla mieleen".

On syytä puuttua vähän tarkemmin näihin vaikutteihin, antaa Koskenniemen itse tehdä niistä selkoa ja siirtyä sitä tietä eräihin hänen ranskalaista kulttuuria, eritoten kieltä ja kirjallisuutta koskeviin tulkintoihinsa. Vuosisadanalun ylioppilaassa Koskenniemi kertoo, miten eräät hänen virolaiset ylioppilastoverinsa, etenkin Suits ja Aavik, jotka hän tapasi usein yhteisessä ruokapaikassa, olivat hyviä ranskalaisen kirjallisuuden tuntijoita eivätkä väsyneet suosittelemasta hänelle myöskään "päivän uusia nimiä" — tästähän myös Lauri Viljanen mainitsee Koskenniemen-elämäkerrassaan. ${ }^{4}$ Ensimmäisenä varsinaisena kirjallisuushistoriallisena ja esteettisenä oppaana ranskalaiseen runouteen oli kuitenkin Emil Zilliacuksen v. 1905 painettu väitöskirja Den nyare franska poesin och antiken (KT IV, s. 375). - Merkityksellistä joka tapauksessa on, että ranskalainen ja osittain myös italialainen kirjallisuus toivat romaanisen vaikutuksen hänen ajatusmaailmaansa aikaisempien yksipuolisesti germaanisten herätteiden vastapainoksi. Varsin huomionarvoinen on Koskenniemen toisessa yhteydessä lausuma arvostelu saksalaisesta proosasta: sen "raskaus ja hämäryys tuntuivat entistäkin painostavammalta" sen jälkeen kun hän oli alkanut lukea myös ranskalaisia kirjoja (KT IV, s. 368).

${ }^{3}$ Rafael Koskimies, V. A. Koskenniemen henkilökuvan piirteitä, Kirjallisuudentutkijain Seuran Vuosikirja 20, Helsinki 1962, s. 181-88.

4 Lauri Viljanen, V. A. Koskenniemi, Porvoo 1935, s. 35.

10 
Pienessä omaelämäkerran hahmotelmassaan (vuosilta 1944 ja 1955) Koskenniemi toteaa, että Saksasta ja Ranskasta käsin tulleet kulttuuriherätteet pitivät toisensa suunnilleen tasapainossa (KT IV, s. 487). Vastakohtaisista aineksista syntyy usein hedelmöittävä ristiriita. Lauri Viljanen arvelee, että Gallian ja Germanian vastakkaisuudessa oli jännitystekijöitä, jotka pyrkiessään sovintoon keskenään rakensivat Koskenniemen persoonallisuutta. ${ }^{5}$ Koskenniemi itse piti saksalaisen ja ranskalaisen olemuksen ja hengen suhdetta yhtenä eurooppalaisen kulttuurin kiihottavimmista, syvällisimmistä probleemeista (KT V, s. 278-79). Monissa yhteyksissä hän esitteli omaa haavettaan nämä vastakohdat sulattavasta korkeammasta synteesistä. Hartain äänenpainoin hän tulkitsee ajatustaan v. 1931 ilmestyneessä esseekirjassaan Symphonia Europaea A.D. 1931. Haaveeseen liittyy toive Saksan ja Ranskan valtiollisesta sovinnosta, kansojen keskinäisen sovun ja ymmärtämyksen mahdollisuudesta (KT V, s. 281).

Yksinkertaistettu ongelma "saksalaisen syvällisyyden ja ranskalaisen kirkkauden, germaanisen Innerlichkeitin ja gallialaisen esprit'n vastakkaisuudesta" on Koskenniemen omakohtaisen syvästi elämä. Huomionarvoinen saksalaisen ja ranskalaisen proosan vertailu osoittaa, minne päin Koskenniemen tyyli-ihanteet olivat jo varhain kehittymässä. Aivan tietoisesti Koskenniemi omien sanojensa mukaan alkoi opiskeluaikanaan tarkkailla muotoa ja kehittää omaa ilmaisuaan ranskalaisten kirjailijain koulussa (KT IV, s. 373, 431). Huomattakoon myös, mitä Koskenniemi "Neljännesvuosisata kirjallisuuden opettajana" nimisessä muistelmassaan sanoo ranskalaisesta kirjallisuudesta oppilaiden tyylivaiston kehittäjänä. Kirjallisten koulujen ja virtausten ja kirjallisuushistorian tuntemuksen kannalta hän sitä paitsi piti Ranskan kirjallisuutta edustavimpana ja 'vanhaa' Gustave Lansonia, "määritelmien mestaria", alallaan voittamattomana (KT IV, s. 498). Kovin monesti ei Koskenniemi esseissään Lansoniin varsinaisesti vetoa. Montaignen yhteydessä hän viittaa ranskalaiseen tutkijaan seuraavasti: "Mutta antiikin stoalaisesta kuoleman halveksimisesta eroaa Montaigne siinä, että siitä puuttuu kaikki ylpeä ja sankarillinen aines. Montaignen ihanne on pikemmin, kuten Lanson on huomauttanut, talonpojan yksinkertainen alistuminen, joka näkee kuolemassa vain jotakin jokapäiväistä ja luonnollista" (KT VI,

5 Lauri Viljanen, emt. s. 165. 
s. 542) ${ }^{6}$ Muuten ei Koskenniemen Montaignen-esittely nojaudu Lansoniin. Muutamat samankaltaisuudet selittyvät samasta selväpiirteisestä kohteesta. Vaikutteiden saanti Lansonilta on ilmeistä - jo Koskenniemen antamien tietojen perusteella. Ranskalaisen laaja kirjallisuushistoria oli ilmestynyt 1894, L'Art de la Prose 1908. Ne ovat siten jo varhain olleet Koskenniemen käytettävissä. Myöhemmin ilmestyneistä Lansonin teoksista voi tulla kysymykseen Methodes de l'histoire littéraire vuodelta 1925. Kenties Koskenniemi on oppinut Lansonilta tietynlaista impressionismia, intuitiivista tulkintatapaa ja historian näköalojen availua. Mutta Lansonin tarkkaa järjestelmällisyyttä ja kielellistä tekstianalyysia ei taas Koskenniemeltä tapaa. On sitä paitsi turha rakentaa ranskalaisten vaikutteiden saantia liiaksi Lansonin varaan. Yhtä hyvin on muistettava Brunetière, Lemaître ja Faguet, joiden Koskenniemi katsoi edustaneen aikansa ranskalaisen kritiikin korkeinta tasoa. Lemaîtren "hieno vaikutusten erittely" ja Faguet'n "henkevä taiteilijapersoonallisuuden luonnehdinta" ovat rinnastettavissa Koskenniemen kriitikonlaatuun.

Puoli vuosisataa kestäneessä kriitikon ja esseistin työssään Koskenniemi esitteli ranskalaista kirjallisuutta jatkuvasti ja runsaasti. Ranskalainen romaani on ollut yhtenä valta-alueena hänen kotikirjastossaan. Ranskan kieltä ja ranskalaisten kirjailijoiden tyyliä hän ei lakannut ihailemasta. Sekä kieli että tyyli vetosivat hänen kriittiseen, esteettisesti vaateliaaseen aistiinsa. Hän ihaili Flaubertin lauseiden "rytmillistä suloa", sanojen läpikuultavaa kirkkautta, "joka tekee kielellisen ilmauksen miltei näkymättömäksi, antaakseen a s i a n loistaa" (KT X, s. 416). Hän puhuu Anatole Francen hienostuneen yksinkertaisesta ja älyllisesti kimaltavasta kertomataiteesta ( $\mathrm{KT} \mathrm{X}$, s. 424-26). Luonnehtiessaan eräässä yhteydessä Henri Bordeaux'n Ranskan Akatemiassa pitämää puhetta Koskenniemi kehittää karakteristiikastaan seuraavan hauskan sivumietteen: "Kuunnellessaan Bordeaux'n melodisia, puolittain ironisia, puolittain ystävällisen hymyn säestämiä periodeja tulee uudelleen vaistomaisesti mieleen, miten barbaarisia kaikki muut kielet ovatkaan ranskan rinnalla ja mikä tavaton kulttuuriperintö sisältyy siihen kielelliseen ilmaisuun, jonka jokainen ranskalainen lapsuudestaan oppii ja jota muukalainen kai-

- Tätä koskeva kohta on Lansonin teoksessa Histoire de la Littérature française (Troisième Edition, Paris 1895, s. 327). 
kesta hyvästä tahdostaan huolimatta ei oikeastaan koskaan kykene omaksumaan" (KT V, s. 319-20).

On selvää, että tämäntapainen 'ranskalaisuuden harrastus' on merkinnyt paljon Koskenniemen oman tyylin kehitykselle. "Meidän mielitekomme ennustavat kohtalomme", voisimme miltei tässäkin tapauksessa sanoa Koskenniemen aforismin mukaan. Lauri Viljanen arvelee Koskenniemen-monografiassaan, että Koskenniemi 1910-luvulla "jatkuvasti oli hengenlaatunsa olennaisimmasta piirteestä, verrattomasta muotokirkkaudesta, suurimmassa kiitollisuudenvelassa ränskalaiselle kulttuurille".? Voisi ehkä sanoa niinkin, että Koskenniemen tyyli oli alusta alkaen siinä määrin valmista "kauniin viivan" ja "plastisen linjan" suuntaan, että voimme olettaa ranskalaisen tyylin vaikutteiden ohjautuneen valmiisiin luontumuksiin.

Koskenniemen esseiden tyylistä voi panna merkille juuri samanlaisia piirteitä kuin hän itse korostaa ranskalaisen tyylin olennaisuuksiksi. Näyttää siltä, että juuri esseissä Koskenniemen impressionistinen proosa toteutuu parhaimmillaan: älyn nopealiikkeisyys, havaintojen terävyys, sanonnan notkeus ja aforistiset kärjistykset synnyttävät yksilöllisten sävyjen ja muotojen vaihtelun, jollaista pidetään esseetyylille edullisena.

Tyypillinen Koskenniemen essee on hahmoltaan selkeä, ilmava, rytmiltään etenevä. Rakenteessa on silti eräänlaista määräisyyttä. Alku on useinkin kauas ulottuvien yhteyksien nopeaa johdattelua; se paisuu joskus mahtavaksi uvertyyriksi, joka suggeroi lukijan havaitsemaan ja vastaanottamaan. Esseen lopussa jokin tyylillinen kärki irrottaa aiheesta vielä jotain tähdellistä tai avaa uuden näkökủlman aforistisena tihentymänä. Näitä tunnusmerkkejä ei voi sanoa sinänsä ranskalaisuuden piirteiksi. On otettava huomioon kokonaisuutta hallitseva sävy, esseen ilme. Koskenniemen essee on avoin: kirjoittajan mielipiteet ja ilmaisun liikkeet näkyvät — ne ikään kuin rientävät lukijaa vastaan, niitä ei tarvitse etsiä eikä aavistella.

Ehkä on paikallaan pieni rakenneanalyysi. Valittakoon Runon kaupungeista essee "Saumur", jonka kohteena on Balzacin Eugénie Grandet romaanin paikallisuus. Essee alkaa tyypillisellä uvertyyrillä:

On olemassa kirjailijoita, joiden henkilöt elävät ympäristössään eristettyä elämää, vailla tiettyä suhdetta johonkin paikkaan tai ajan-

7 Lauri Viljanen, emt. s. 163. 
kohtaan. Heidän ihmisensä kansoittavat eräänlaisia abstraktisia seutuja, maita tai kaupunkeja, joista puuttuu yhteiskunnan, kansallisuuden, historiallisen aikakauden, vieläpä joskus tietyn roduinkin tuntomerkit. On taas toisia kirjailijoita, joiden henkilöt ovat niin läheisessä suhteessa ympäristöönsä, että ne tuntuvat saavan varsinaisen elämänsä vasta tässä tietyssä paikassa. Niiden kaupungit voi löytää maantieteestä ja niiden elinajan historiasta. Niin kuin isäjumala loi ihmisensä vasta kuudentena luomispäivänä, niin nämä kirjailijatkin luovat henkilönsä, Iuotuaan ensin kaikki edellytykset niiden olemassaololle. He rakentavat mielikuvituksessaan kaupungin, kadun, talon, missä heidän sankarinsa ja sankarittarensa asuvat, antavat puiden viheriöidä tai kellastua vuodenaikojen mukaan, panevat linnut aamuin laulamaan ja katulyhdyt illoin palamaan, pilvet purjehtimaan taivaalle ja puhaltavat vihdoin jonkun historiallisen aikakauden tunnelman tähän mielikuvituksensa maailmaan. Vasta sen jälkeen tulee runoteosten sankarien vuoro. Kirjailija pudottaa heidät tähän kuolleeseen maailmaan niin kuin kemisti pudottaa seoksiinsa pisaran voimakasta eliksiiriä, joka panee nesteet kuohumaan ja synnyttää liikettä ja elämää. Kaduilla alkaa vilinä, ovet alkavat käydä, sydämet lyödä, intohimot nousta ja laskea, ratas tarttuu rattaaseen, elämän punainen virta hyökyineen ja suvantoineen syöksähtää näihin valmiisiin uomiin. Kirjailija on tullut luomistyönsä kuudenteen päivään.

Tällä tavalla loi mm. Ranskan naturalistisen romaanin isä Honoré de Balzac... .

Tämän jälkeen nousee Saumur huomion keskipisteeksi. Myös esseen kirjoittaja astuu èsiin. Omakohtainen käynti Saumurissa luo yhteydet kahden ajankohdan välille: esseen nykyishetki johtaa suoraan Balzacin romaanin maailmaan. Seuraa vaihtelevan impressionistinen jakso omakohtaisia huomioita, joilla kaikilla on yhteys Balzacin romaaniin. Jakson lopulla on ratkaiseva tihennys: "Ja minulle käy äkkiä selväksi, minkä tähden Balzac on sovittanut kertomuksen juuri näihin puitteihin: toisella puolen rikas, antelias luonto, joka tuntuu kutsuvan ihmiset yksinkertaiseen onnelliseen elämään, toisella puolen ihmisyhteiskunta, joka muuttaa luonnon nesteet kiiltäviksi kolikoiksi, unohtaen kaiken muun maailmassa paitsi keltaisen metallin arvon." Tämän jälkeen on täsmentävää romaaniaiheen kommentointia ja tulkintaa. Taas uusi impressionistinen jakso, josta yhteydet interpretaatioon. Sitten vielä Balzac ja Eugénie Grandet rinnakkain ja romaanin rajallinen yleisarviointi, joka sekin saa elävyyttä parista impressiosta: 
Balzacin romaanilta puuttuu kaikki viimeistelty taiteellinen täydellisyys, niin kuin niiltä puisilta korkokuvilta, jotka koristavat muutamien Saumurin talojen päätyjä. Mutta se on piirtynyt näihin homehtuneihin seiniin lähtemättömämmin kuin vanhojen mestarien veistokset. Matalasta, pölyttyneestä, rautapuomeilla varustetusta ikkunasta, johon keksin itseni tähyilemästä, luen salaperäisiä hieroglyfejä, luen kullasta ja rakkaudesta, Eugénie Grandet'sta, vilpittömyydestä, joka sortuu itsekkyyden jalkoihin.

Erillisenä päätekappaleena on vielä hieman yllättävä tihennys:

Ja Saumur on minulle niitä kaupunkeja maailmassa, joissa i h$\mathrm{m}$ i s e ll ä on kotipaikkaoikeus.

"Saumur" esseen rakenne on sekä selkeä että vaihteleva. Yleissävyä voi luonnehtia eloisaksi. Juuri tällainen eloisuus ja kirkkaus ovat Koskenniemen esseiden olennaisuutta.

Ranskalaisten vaikutteiden näkymistä syntaksissa on huomattavasti vaikeampi osoittaa. Se vaatisi paljon tarkempia ja perusteellisempia tutkimuksia, kuin vielä on valmiina.

On tietysti otettava lukuun ranskan ja suomen kielen erilaisuus. Seuraavassa pieni kokeilu. Tyylien psykologiassaan Henri Morier vertailee aika sattuvasti saksan ja ranskan lauserakenteita. ${ }^{8}$ Saksalaiseen ilmaisuun kuuluu kokonaisuuden näkeminen - virkkeessä on synteesin luonnetta:

Wenn heute die Sonne nicht aufgehen sollte, dann hörte auch jede menschliche Tätigkeit auf dieser Erde für immer auf.

On ikään kuin pakko alusta lähtien nähdä loppuun asti koko periodi. - Ranskalainen taas erittelee ajatuksen, etenee ponnahdus kerrallaan ja näyttää voivan pysähtyä loogisen ketjun joka renkaan kohdalle:

Toute activité $[+$ humaine $]$ cesserait $[+$ sur cette terre $]+[a ̀$ jamais $],+[$ si le soleil ne devait pas se lever $]+[$ aujourd'hui $]]$.

Jos me puolestamme jatkamme vertailua sovittamalla mukaan suomenkielisen vastineen, voimme suurin piirtein noudattaa joko saksalaista tai ranskalaista käytäntöä - lauserakenteemmehan on harvinaisen joustava. Siis saksalaisittain:

8 Henri Morier, emt. s. 59. 
Jos aurinko ei tänään nousisi, silloin pysähtyisi myös kaikki inhimillinen toiminta täällä maan päällä ainiaaksi.

Ja ranskalaisittain:

Kaikki inhimillinen toiminta pysähtyisi [ + täällä maan päällä] + [ainiaaksi], $+[$ [jos aurinko ei nousisi] + [tänään $]]$.

Täysin vastaaviksi emme rakenteita saa: sanajärjestykseen ja verbiaineksiin jää eroja. Saksan kielen mukainen rakenne on käsillä olevassa esimerkissä ehkä luontevampi. Mutta on mahdollisuuksia edetä myös progressiivisen ranskan suuntaan.

Minkä arvoinen tämä huomio on? Eihän siitä kovin paljon voi päätellä. Ehkä sentään sen verran, että mahdollisesti kiinnostumme tutkimaan asiaa: Onko ranskan lauserakenne päässyt vaikuttamaan kielemme kehitykseen? Onko Koskenniemi 'ranskalaisuudessaan' antanut suuntaa? Toistaiseksi on tyydyttävä vain ylimalkaisiin olettamuksiin.

Koskenniemi on rakentanut virkkeensä usein holvikaaren muotoon - sitähän olisi ainakin Morier'n mukaan pidettävä saksalaisena piirnteenä. Näin:

"Jos voisimme ajatella, että joku ryhtyisi lukemaan Aleksis Kiven kirjeitä tietämättä ennakolta mitään niiden tekijästä, voisimme siitä huolimatta olla varmat, että lukija saisi voimakkaan vaikutelman hyvin omalaatuisesta ja epätavallisesta persoonallisuudesta" (KT) VI, s. 175).

Mutta vielä tavallisempaa Koskenniemellä on progressiivinen rytmi:

"Elämä pitää puoliaan. Kuolemalla ei ole kotipaikkaoikeutta maan päällä. 'Kuolleen Brüggen' hiljaisiin ylimyksellisiin suojiin astuu 'Elävä Brügge' remuisassa bacchuskulkueessa, rumana ja kömpelönä, huolettomasti tanssien sen Demonin tahdin mukaan, joka täällä maan päällä pitää huolta siitä, ettei leikki lakkaa” (KT V, s. 68).

Kovin paljon varmaa ei vielä voi sanoa tällaisista seikoista tarvittaisiin perusteellisempia tutkimuksia. Jotakin voi päätellä siitä, että Koskenniemi aloittaa virkkeensä usein painavalla toteamuksella, että hän käyttää runsaasti relatiivilauseita, jotka liittävät mukaan määrityksiä ikään kuin jälkeenpäin. Progressiivisuuteen kuuluu myös runsas kaksoispisteen käyttö. Kaksoispistehän synnyttää selvärajaisen 
tauon, josta ilmaisu ponnahtaa eteenpäin. Kaksoispiste rakentaa nopeita yhteyksiä, vapauttaa turhista selittelyistä.

Koskenniemen lauserakenteet ovat selkeitä. Kovin laajoiksi hän ei virkkeitään rakentanut. Hän ei käyttänyt lainkaan puolipistettä. Hän piti merkkiä täysin tarpeettomana: ilmeistä pyrkimystä rakenteiden yksinkertaisuuteen.

Tiiviitä femnistisiä lausemuotoja Koskenniemi ei ole suosinut. Yleensä hänen lauseissaan ovat mukana tavalliset tarpeelliset rakenneyksiköt.

Vierasperäisten sanojen suosinta on aikanaan herättänyt huomiota. Käytössä ilmenee keskeisenä täsmällisyyden tavoittelu. Monen vierasperäisen ilmaisun korvaaminen suomalaisella vaatisi kiertotietä tai johtaisi epämääräiseen 'sinne päin' ilmaisuun. Tarkattakoon seuraavièn näytteiden vierasperäisyyksiä. Sitaatit ovat "Kupolin alla" nimisestä Symphonia Europaea -kirjan esseestä:

Odottaessani toimituksen alkua tulee mieleeni, miten Paul Bourget oli joskus valittanut kaiken muuttuvaisuutta, ajan dekadenssia ja barbarian hiljaista, mutta varmaa voittokulkua. Kaikessa pessimismissään hän näki sentään jotakin kestävääkin — näki eräitä turvallisia, historiaa luovia voimia keskellä pelottavasti lisääntyvää kaaosta. Nämä voimat saivat hänen mielikuvituksessaan neljän instituution hahmon: ne olivat kardinaalikollegio, Englannin ylähuone, Saksan yleisesikunta ja Académie Française.

Jokainen, joka on lukenut Bordeaux'n romaaneja, tietää, että hänellä on ikään kuin kahdet kasvot: toiset sentimentaaliset ja moraalisesti huolestuneet, sopivat missiromaanien tekijälle, toiset henkevät ja ironiset, joiden takaa katsoo skeptikko ja maailmanmies.

Paul Valery on matemaatikko ja intellektualisti, klassillisen linjan ehkä johdonmukaisin puolustaja tämänpäiväisessä ranskalaisessa runoudessa, eräänlaisen tietoisen lyı'iikan teoreetikko ja praktikko, muukalaisen mielestä kylläkin jonkin ver'ran pingottunut ilmaisussaan ja ajatuksissaan.

Täsmällisyyttä koskee myös vierasperäisten ilmaisujen impressionistinen käyttö. Yksi Koskenniemen kielellisistä aforismeista kuuluu näin: "Me voimme yhdessä sanassa tuntea tuoksun kokonaisesta kulttuurista, niin kuin me voimme yhden kukan tuoksussa tuntea koko kevään."

Varsinkin ranskalaisia aiheita käsittelevissä esseissään Koskenniemi viljelee sitaatinomaisia ranskalaisia ilmaisuja oikean sävyn syninyttämiseksi: 
Ja Bordeaux innostuu lyyrillisen kaunopuheiseksi kuvatessaan syntyperäisten bardien laulaman Bretagnen ihanuutta, tuota maanäärtä, josta sen vanhat runoilijat ovat laulaneet, että se on 'le plus beau des pays'.

Muuallakin kuin ranskalaisissa aiheissa on vierasperäisyyksistä latinalais-ranskalaisilla aineksilla Koskenniemen esseetyylissä valtasija. Ne kuuluvat hänen tyylinsä ranskalaiseen ilmeeseen.

Koskenniemen esseetyylin sanasto on kirjakielemme tyypillistä perusmateriaalia. Se pysyttelee jokseenkin vakiona, uudistermejä ja muoti-ilmaisuja kaihtavana. Koskenniemen aforismi "Todellinen tyylitaituri tunnetaan hänen kyvystään esittää vanhoilla sanoilla uusia asioita" valaiisee erinomaisen hyvin myös hänen omaa tyyliään. Koskenniemen esseetuotanto ulottuu 1910-luvulta 1960-luvulle. Sen kohteiden piiriin mahtuu monenlaisia kirjallisia ilmiöitä, useita aikanaan aivan uusia asioita.

Uusien asioiden esittäminen vanhoilla sanoilla vaatii todella tyylitaitoa. Sen ei tarvitse johtaa yksitoikkoisuuteen. Koskenniemen sanonnassa on vaihtelua: sekä tiiviyttä että runollista retorisuutta. Kehitys on kulkenut suurin piirtein karusta hienostuneisuudesta laajeneviin, maalauksellisiin periodeihin ja hieman pateettisiin äänenpainoihin ja viimeisinä vuosikymmeninä taas yksinkertaistumiseen, retorisuuden karsiutumiseen.

Koskenniemen tyylissä on myös vanhentuneiksi katsottavia pïirteitä, pikku heikkouksia. Pääominaisuuksiltaan se on selkeää: sanat ovat täsmällisiä, kuvat selväpiirteisiä, ironiakin läpikuultavaa. Voidaan puhua selkeästä esseistisestä linjasta, jossa ilmaisun kirkkaus korostuu eri stilististen välineiden käytössä aina kaksoispisteitä ja muita merkkejä myöten. Puhumalla erinäisten piirteiden 'ranskalaisuudesta' voimme tähdentää suuntaa antavaa tyylipyrkimystä: vastapainona suomalaisen tyylimme raskasliikkeisyydelle ja pleonastisuudelle on ranskalaisesti notkean ja kirkkaan muodon toteuttaminen vaikuttanut edullisesti kirjakielemme kehitykseen. Kun tämän toteamme, meidän on samalla nähtävä 'ranskalaisuuden' takaa ihminen itse, yksilö, V. A. Koskenniemi, jonka esprit, Gemüt, Innerlichkeit toteutuu juuri hänen tavassaan nähdä, arvostella ja arvioida, kirjoittaa esseensä: aloittaa ja lopettaa, perustella ja väittää, rakentaa lauseensa ja valita ilmaisimensa. 


\section{Pekka Mattila: Einige französische Züge im Stil von V. A. Kosken- niemis Essays}

V. A. Koskenniemis umfangreiche Essayproduktion umspannt die Zeit von ungefähr 1910 bis zum Beginn der 1960er Jahre. Schon in der Ausbildung empfing sein Stil entscheidende französische Impulse, denn schon früh, etwa um 1900, begann der junge Dichter, seine Ausdrucksweise dem Vorbild französischer Verfasser nachzubilden. Die Klarheit des französischen Stils appellierte an seinen kritischen, hohe ästhetische Forderungen stellenden Geschmack.

In Koskenniemis Essays findet man stilistische Züge, die von ihm selbst als wesentliche Eigenheiten des französischen Stils hervorgehoben werden: die Worte sind exakt eingesetzt, die Bilder ausgeprägt, sogar die Ironie ist kristallklar. Der Rhythmus seiner Essays ist progressiv, ihre Gestalt klar, luftig, offen: Die. Ansichten des Verfassers und die Bewegungen des Ausdrucks liegen offen, sich gleichsam dem Leser darbietend; es ist nicht nötig, sie zu suchen oder zu erahnen. Gerade in den Essays zeigt Koskenniemis impressionistischer Prosastil sich von seiner besten Seite: durch Zusammenwirken seines beweglichen Intellekts, der Schärfe seiner Beobachtungen, der Anpassungsfähigkeit seiner Ausdrucksweise und seiner aphoristischen Zuspitzungen entsteht ein wohltuender Wechsel der Nuancen und Formen. Die Ausdrucksklarheit wird durch die Anwendung verschiedenartiger stilistischer Mittel, sogar durch die Interpunktion betont. Der Wortschatz bleibt sich ziemlich gleich, der Dichter scheut Modeausdrücke und neue Wortbildungen. Von seinem Streben nach Exaktheit und unverfälschten Nuancen zeugt die Bevorzugung von Fremdwörtern.

Schwerfälligkeit und Pleonasmus heissen die beiden Fallgruben für den finnischen Ausdruck. Durch Koskenniemis richtungweisenden, französisch biegsamen, von schillernder Intelligenz geprägten, eleganten Stil wurde die Entwicklung unserer Schriftsprache in günstiger Riehtung beeinflusst. 